The costs of production of alternative jet fuel: A harmonized stochastic assessment Peer-reviewed author version

Bann, Seamus; MALINA, Robert; Staples, Mark D.; Suresh, Pooja; Pearlson, Matthew; Tyner, Wallace E.; Hileman, James \& Barrett, Steven (2017) The costs of production of alternative jet fuel: A harmonized stochastic assessment. In:

Bioresource technology, 227, p. 179-187.

DOI: 10.1016/j.biortech.2016.12.032

Handle: http://hdl.handle.net/1942/22955 


\title{
The costs of production of alternative jet fuel: a harmonized stochastic assessment
}

\author{
Seamus J. Bann ${ }^{\mathrm{a},}$, Robert Malina ${ }^{\mathrm{a}, \mathrm{b}, 1}$, Mark D. Staples ${ }^{\mathrm{a}}$, Pooja Suresh ${ }^{\mathrm{a}}$, Matthew Pearlson ${ }^{\mathrm{a}}$, \\ Wallace E. Tyner ${ }^{\mathrm{c}}$, James I. Hileman ${ }^{\mathrm{d}}$, Steven Barrett ${ }^{\mathrm{a}}$ \\ ${ }^{a}$ Laboratory for Aviation and the Environment, Massachusetts Institute of Technology, 77 Massachusetts Avenue, \\ Cambridge, Massachusetts 02139, United States \\ ${ }^{\mathrm{b}}$ Center for Environmental Sciences, Hasselt University, Martelarenlaan 42, 3500 Hasselt, Belgium \\ ${ }^{\mathrm{c}}$ Department of Agricultural Economics, Purdue University, 403 W. State Street, West Lafayette, IN 47907, United States \\ ${ }^{\mathrm{d}}$ United States Federal Aviation Administration, 800 Independence Avenue, S.W., Washington, D.C., United States
}

\begin{abstract}
This study quantifies and compares the costs of production for six alternative jet fuel pathways using consistent financial and technical assumptions. Uncertainty was propagated through the analysis using Monte Carlo simulations. The six processes assessed were HEFA, advanced fermentation, Fischer-Tropsch, aqueous phase processing, hydrothermal liquefaction, and fast pyrolysis. The results indicate that none of the six processes would be profitable in the absence of government incentives, with HEFA using yellow grease, HEFA using tallow, and FT revealing the lowest mean jet fuel prices at $\$ 0.91 /$ liter $(\$ 0.66 /$ liter-\$1.24/liter), $\$ 1.06 /$ liter $(\$ 0.79 /$ liter- $\$ 1.42 /$ liter), and $\$ 1.15 /$ liter $(\$ 0.95 /$ liter-\$1.39/liter), respectively. This study also quantifies plant performance in the United States with a Renewable Fuel Standard policy analysis. Results indicate that some pathways could achieve positive NPV with relatively high likelihood under existing policy supports, with HEFA and FPH revealing the highest probability of positive NPV at $94.9 \%$ and $99.7 \%$, respectively, in the best-case scenario.
\end{abstract}

Keywords: Alternative jet fuel; techno-economic analysis; Monte-Carlo simulation; United States alternative fuel policy; Renewable Fuel Standard

\footnotetext{
${ }^{1}$ Corresponding author, Email: robert.malina@uhasselt.be Tel.: +32-11-268687
} 


\section{Introduction}

Aviation currently contributes $2 \%$ to anthropogenic GHG emissions (ICAO, 2010). The impact is expected to grow in the absence of mitigation measures, due in part to a projected annual industry growth (measured in revenue passenger kilometers) of approximately 5\% out to 2034 (Boeing, 2015). The aviation industry's $\mathrm{CO}_{2}$ emissions have grown by $3.6 \%$ per year since 1980 , or approximately double the current world growth rate of $\mathrm{CO}_{2}$ emissions from energy consumption, prompting attention from numerous international and domestic regulatory authorities (Schäfer, 2014). The International Air Transport Association (IATA), for example, targets carbon-neutral growth from 2020 onward and a 50\% reduction in net emissions by 2050 compared to 2005 levels (IATA, 2009). Alternative jet fuels produced from biomass have received considerable attention from policy-makers and academia as a potential means to significantly reduce greenhouse gas emissions attributable to aviation (ICAO, 2016). The United States Federal Aviation Administration (FAA), for example, sets an aspirational consumption target of 1 billion gallons of alternative jet fuel by 2018 , and alternative jet fuel can qualify under the second iteration of the Environmental Protection Agency's (EPA) Renewable Fuel Standard (FAA, 2012). Emissions savings attributable to alternative jet fuels have been well-documented in several pathway- and feedstock-specific life cycle GHG emission analyses (Seber et al., 2014; Staples et al., 2014; Suresh, 2016).

One of the main challenges for aviation biofuels is the economic feasibility of converting biomass into liquid fuel that meets current jet fuel specifications. Five pathways have been approved by ASTM International as drop-in alternative jet fuels: Fischer- 
Tropsch Synthetic Paraffin Kerosene (FT-SPK), Fischer-Tropsch Synthetic Kerosene with Aromatics (FT-SKA), Hydroprocessed Esters and Fatty Acids (HEFA), Synthetic IsoParaffins from fermented hydroprocessed sugar (SIP), and Alcohol-to-Jet SPK (ATJ-SPK). 16 additional pathways are under review (CAAFI, 2016). ASTM certification associated with fuels produced from these pathways allows up to $50 \%$ blending by volume in current aircraft engines, and some of these pathways, as a result, have been implemented in first-oftheir-kind commercial scale production facilities (ICAO, 2016).

This paper describes a techno-economic study that used harmonized assumptions for six different alternative jet fuel pathways and incorporated uncertainty throughout the analysis. Existing studies estimated costs of production for specific pathways or feedstocks through detailed techno-economic analyses (TEA) that evaluated pathway performance by calculating the breakeven price of fuel or the net present value of the plant over the modeled refinery's lifetime (Bittner et al., 2015; Bond et al., 2014; Niziolek et al., 2015; Pearlson et al., 2013; Staples et al., 2014; Zhu et al., 2014). Although considerable uncertainty surrounds critical variables such as fuel prices, conversion yield, and capital expenditures, few studies to date have incorporated stochasticity in the modeled pathways or have examined the diesel and jet fuel industry specifically (de Jong et al., 2015). This paper incorporates both harmonized assumptions and stochasticity in critical inputs and accounts for different policy scenarios in a harmonized comparison of jet fuel production techniques. 


\section{Materials and Methods}

\subsection{Alternative jet fuel pathway modeling}

This study compared 6 alternative jet fuel pathways for which data is available in peerreviewed studies: HEFA, fermentation and advanced fermentation (AF), aqueous phase processing (APP), conventional gasification and Fischer-Tropsch (FT), hydrothermal liquefaction (HTL), and fast pyrolysis and hydroprocessing (FPH). The source literature and information regarding the feedstocks and liquid fuel products for each pathway is found in Table 1. A technical survey of each pathway can be found in SOM 1 and the technical assumptions used in the original literature sources can be found in SOM2, Table S3. In every case, the products are chemically equivalent to conventional products of petroleum refining, with the middle distillate fraction composed of renewable or "green" diesel and kerosene-type jet fuel.

\begin{tabular}{|c|c|c|c|}
\hline Pathway & Feedstock & Fuel products & Source \\
\hline HEFA & $\begin{array}{l}\text { Soybean oil, tallow, } \\
\text { yellow grease }\end{array}$ & $\begin{array}{l}\text { LPG, naphtha, } \\
\text { middle distillates }\end{array}$ & $\begin{array}{l}\text { Pearlson et al., } \\
\text { 2013; Seber et al. } \\
2014\end{array}$ \\
\hline $\mathrm{AF}$ & $\begin{array}{c}\text { Corn grain, } \\
\text { sugarcane, } \\
\text { herbaceous biomass }\end{array}$ & $\begin{array}{l}\text { LPG, naphtha, } \\
\text { middle distillates }\end{array}$ & Staples et al., 2014 \\
\hline APP & Woody biomass & $\begin{array}{l}\text { LPG, naphtha, } \\
\text { middle distillates }\end{array}$ & Bond et al., 2014 \\
\hline HTL & Woody biomass & $\begin{array}{l}\text { Gasoline, heavy oil, } \\
\text { middle distillates }\end{array}$ & Zhu et al., 2014 \\
\hline FT & MSW & $\begin{array}{l}\text { Gasoline, middle } \\
\text { distillates }\end{array}$ & $\begin{array}{l}\text { Niziolek et al., } \\
\text { 2015; Suresh et al., } \\
2016\end{array}$ \\
\hline $\mathrm{FPH}$ & Corn stover & $\begin{array}{l}\text { Gasoline, middle } \\
\text { distillates }\end{array}$ & $\begin{array}{l}\text { Bittner et al., 2015; } \\
\text { Brown et al., } 2013\end{array}$ \\
\hline
\end{tabular}

Table 1. The six alternative jet fuel production pathways evaluated in this study. 
The surveyed pathways are at various stages of technical maturity, and discrepancies in commercialization were accounted for with a $n t h$ plant analysis that assumes construction in 2015 and plant operation beginning in 2018. The design bases for the pathway models, however, varied with the availability of bench-, pilot- or commercialscale process data, so this study assumed equivalent fuel yields at scale in each case. This study compared each pathway using material and energy balances from the sources found in Table 1, but the original TEAs of the pathways relied on deterministic fuel yields and capital cost estimates as well as historical averages for input and output prices. Point values for these model components were then used in a Discounted Cash Flow Rate of Return (DCFROR) model that was used to determine either the net present value (NPV) of the plant assuming market fuel prices or the minimum middle distillate selling price (MSP) such that the NPV was positive. Assuming that prices for inputs and outputs were certain throughout a plant's lifetime, however, failed to account for fluctuations in the costs of key inputs or the prices of fuel products. The original TEA studies associated with each pathway used DCFROR variables with deterministic values, but in reality these variables change stochastically such that sampling values from probabilistic models provided a better model for input value fluctuation over a plant's lifetime.

Blazy et al. used the example of diesel fuel price, which can be affected by a multitude of external forces such as supply shocks, changes in demand, or adjustments to domestic policy (Blazy et al., 2016). Using a single value for the price of diesel ignored these fluctuations. Instead, correlating the price of diesel to stochastic variations in the projected price of gasoline provided a more robust description of how this input changed over time. Instead of varying independently with time, other fuel products were also 
correlated to the stochastically projected price of gasoline. This study implemented stochasticity using a Monte Carlo simulation that sampled values from probability distributions assigned to critical inputs. A MATLAB model sampled values from each probability distribution, computed either MSP and NPV over 10,000 iterations, and stored the results for each iteration such that each iteration was a discrete 20 -year plant lifetime.

\subsection{Financial model}

This study employed a MATLAB version of the DCFROR model from Pearlson et al. in order to quantify pathway performance in terms of MSP and NPV (Pearlson et al., 2013). Financial assumptions were harmonized for each pathway assuming a 20 -year plant lifetime with $20 \%$ equity financing and a 10-year loan with $10 \%$ interest. Each plant was assumed to operate for 8400 hours, or 350 days, per year. The income tax rate was assumed to be $16.9 \%$ based on the value for the average effective corporate tax rate from the United States Government Accountability Office (GAO, 2013). Other financial assumptions were drawn from Blazy et al.’s research on bio-process commercialization (Blazy et al., 2016). All costs and prices were expressed in 2015 USD.

The critical inputs for the DCFROR model were assessed using the relevant studies associated with each pathway, and probability distributions were assigned to each input given the availability of relevant data. The complete table of parameters, their distributions, and the references associated with the data underlying each distribution was included in the SOM 2, Table S2. Probabilistic inputs that were common between pathways include capital expenditures, fixed operating costs, feedstock costs, and fuel prices. The parameter distributions were primarily dependent on the available data: uniform distributions were 
used in cases where data values were equally likely and triangular or beta PERT

distributions were used when minimum, maximum, and most likely values were known. In cases of statistical uncertainty arising from descriptive data sets, such as historical commodity prices or price projections, the probability distributions were developed from the samples themselves. The fit of these distributions was confirmed using the AndersonDarling test (Stephens, 1974).

The feedstock input quantities and associated maximum fuel outputs can be found in SOM2, Table S4. Due to the price parity between diesel and jet fuel the model solved for the MSP of middle distillates (i.e. jet and diesel). The MSP for middle distillate fuels was calculated as the price for middle distillates such that the refinery has an NPV of zero. The MSP thus represents the price for middle distillates that a producer must demand in order to achieve a target rate of return. All other products, such as naphtha or LPG, were sold at the sampled market price and not at a correlated premium, a method used in previous TEA studies (Pearlson et al., 2013). The costs of transportation from the plant to the retail location were not considered, nor were additional fuel taxes, so the MSP and other product prices are the "gate price" of the fuel and not the at-pump price. The DCFROR model was also used to calculate the NPV of each pathway assuming market prices for all fuel products. A positive NPV implies that a producer can expect profits above the target rate of return, while a negative NPV implies net losses below a target rate of return. MSP and NPV calculations were chosen as metrics for plant performance due to literature precedent and due to ease of visual comparison. 


\subsection{Technical uncertainty}

\subsubsection{Capital investment and fixed operating cost uncertainty}

The capital cost estimates for each refinery model were obtained from the literature studies used to determine the mass and energy balances for the pathways examined in this study. The deterministic pathway capacity was fixed to 111.3 million liters/year (2000 barrels/day) a reference capacity used for many of the original case processes (Pearlson et al., 2013; Staples et al. 2014; Niziolek et al. 2015). This output capacity varied, however, with stochastic changes in fuel yield. Plant utility requirements, feedstock inputs, and product slates were normalized to a 111.3 million liters/year output capacity in cases where the reference pathways produced greater volumes of liquid fuels (Bond et al. 2015; Zhu et al. 2014; Bittner et al. 2015). This study assumed greenfield plants with onsite hydrogen production, and it is noted that capital and operating costs might be reduced with brownfield sites purchasing offsite hydrogen. The feedstock inputs and fuel outputs for each pathway are summarized in SOM 2, Table S4.

Where data availability allowed, plant component cost estimates and fuel yields were harmonized between pathways. For example, the fatty acid hydroprocessing steps in the AF models employed by Staples et al. used the utility cost, capital cost, and conversion yield estimates calculated by Pearlson et al.'s HEFA study (Staples et al. 2014). Due to diverse simulation techniques (using Aspen Plus ${ }^{\mathrm{TM}}$, ChemCAD $\odot$, or mathematical models) and conversion data sources (bench tests, industry heuristics), this study assumed that the deterministic capital expense values accurately reflect the investment requirements for each

process. Because this study further assumed that construction for each plant begins in 2015, 
the capital costs were adjusted to 2015 USD using the Chemical Engineering Plant Cost Index (Chemical Engineering, 2016).

In order to incorporate uncertainty into the capital cost figures, the error associated with deterministic cost estimates was assumed to be $\pm 20 \%$ (Gary et al., 2007). A review of other biomass-to-jet fuel studies revealed that the capital costs for similar plant components fall within this range. Previous studies employed a triangular or beta PERT distribution given mode, minimum, and maximum values, and a beta PERT distribution was employed in this case (Bittner et al., 2015; Blazy et al., 2016; Zhao et al., 2015). Brown found that an asymmetric probability distribution with positive skewness best represented current capital expenditures, and a 5\% mean cost overrun was assumed based on a survey of the literature for a variety of industrial plants and construction projects (Brown, 2015). As a result, a beta PERT distribution for fixed capital investment (FCI) that varies between $80 \%$ and $150 \%$ of the deterministic value was used in order to replicate these conditions. Following an assumption found in several preceding TEA studies for these pathways, working capital (WC) was assumed to be 5\% of the FCI, and the sum of these two values was the total capital investment (TCI) (Peters et al., 2003; Pearlson et al., 2013; Staples et al. 2014; Bond et al., 2014).

Fixed operating costs (FOC) was determined as a percentage of the capital costs, but each pathway cited widely varying deterministic values that correspond with differences in estimates of yearly expenses such as labor and maintenance. Insurance, local taxes, maintenance, and contingency costs for each pathway were estimated using guidance from the petroleum refining industry, and the literature FOC as a percentage of FCI was selected 
as the mode for a positively-skewed beta PERT distribution with harmonized parameters (Gary et al., 2007). Each pathway's FOC was varied by $\pm 50 \%$ and values beyond the bounds of this distribution were investigated in the sensitivity analyses.

\subsubsection{Fuel yield uncertainty}

The conversion efficiency of each pathway was described by assigning a probability distribution to fuel yield in terms of liters of gasoline equivalent (LGE) per metric ton of feedstock. The energy shares of each fuel product, expressed as the energy content of each fuel product (in MJ) divided by the total energy content of the product slate (in MJ), was assumed to remain constant for each pathway. In literature refinery models where diesel was the only middle distillate product, this study followed Bittner et al. and assumed that this stream was $50 \%$ jet fuel and 50\% diesel by volume when calculating NPV (Bittner et al., 2015). Previous studies that incorporated fuel yield uncertainty employed a variety of probability distributions based on bench-scale data or simulation results including beta general distributions, beta PERT distributions, and triangular distributions (Zhao et al., 2014; Petter and Tyner, 2014; Zhu et al., 2003). In this case, a lack of fuel yield data dictated the use of a beta PERT distribution with some minimum, maximum, and mode value using the method employed by Suresh and Petter and Tyner (Suresh, 2016; Petter and Tyner, 2014). Following Zhao et al., a negatively-skewed beta PERT distribution was assumed based on pathway-specific supporting data. In pathway cases with only one supporting study, such as HEFA, AF, and APP, the deterministic value was used as the maximum fuel yield value. Because of the negative skewness, the distribution mean was 
lower than the deterministic value. In order to illustrate the different fuel yield scenarios, the upper and lower bounds of this distribution were investigated in the sensitivity analyses with the original literature value used as the upper input. The distribution parameters and their references can be found in SOM 2, Table S2.

\subsection{Fuel and energy price uncertainty}

In order to project the prices of natural gas, electricity, and gasoline from the analysis start point in 2018 through the plant's 20-year lifetime, Geometric Brownian Motion (GBM) was applied according to the method described in Zhao et al. as shown in Equation 1:

$$
P_{t}=P_{t-1} \times e^{r}+\varepsilon
$$

where $P_{t}$ is the price at time $t, P_{t-l}$ is the previous year's price, $r$ is the growth rate, and $\varepsilon$ is the yearly price variation (Zhao et al., 2014). The Energy Information Administration (EIA) Annual Energy Outlook (AEO) 2015 provides projected price data in the analysis start year (2018) as well as real price growth rates from 2018 to 2038, with low, reference, and high oil price scenarios describing the behavior of these prices over time (EIA, 2015). Uncertainty was incorporated in the gasoline growth rate and the 2018 start price by assigning a beta PERT distribution to both parameters using the oil price scenarios as low, mode, and high values. The starting prices and growth rates for natural gas and electricity were then correlated with the selected gasoline values (EIA, 2016a,e). The 2018 prices of gasoline, natural gas, and electricity from the AEO reference case projections are $\$ 0.58 /$ liter, $\$ 5.02 / \mathrm{GJ}$, and $\$ 0.07 / \mathrm{kWh}$, respectively (2015 USD). The yearly price variation 
term, $\varepsilon$, was selected from a normal distribution of the year-to-year variations in prices from the past 15 years from 2001 to 2015. Although the MATLAB model was constructed to ensure that prices remain positive, values selected from the outer bounds of the variation distribution can result in prices far above or far below prices seen in historical or projected datasets. Prices were prevented from dropping below $75 \%$ of the lowest forecasted value or rising above $125 \%$ of the highest forecasted value in order to correct for this error.

The prices of other fuel products, such as LPG, jet, and diesel, were correlated with the gasoline price using historical price data from the EIA (EIA 2016b,c,d,f). Following Pearlson et al. and Staples et al., the propane spot price was used as a surrogate for both light ends and LPG and the gasoline price was used as a surrogate for naphtha (Pearlson et al., 2013; Staples et al., 2014). The correlation functions for these fuels were based on their historical regression relationship and can be found in SOM 2, Table S5.

\subsection{Policy uncertainty}

In order to quantify uncertainty under various policy scenarios including the Renewable Fuel Standard (RFS2), this study modeled the price behavior of fuel credits called Renewable Identification Numbers (RINs) using probability distributions and incorporated various tax credit scenarios as sensitivity analyses. Under RFS2, blenders and refiners are required to incorporate a certain quantity of biofuels in their annual supply in order to meet their Renewable Volume Obligation (RVO). Renewable fuels generate RIN certificates, which can be bought and sold to help blenders and refiners achieve their RVO; as a result, RINs represent a source of additional revenue for biofuel producers (ICCT, 
2014). The nationwide RVO increases every year up to 36 billion gallons in 2022 . At the conclusion of 2022, the RVO could be extended, increased, or reduced with the passage of a new RFS, thus changing the RIN market substantially (Winchester, et al., 2013).

Information regarding the implementation of RINs for each fuel product and the calculation of stochastic RIN prices can be found in SOM 4.

The Biodiesel Mixture Excise Tax Credit, which can be applied to both biodiesel and renewable diesel mixtures, is a $\$ 1.00 /$ gallon $(\$ 0.26 /$ liter $)$ credit applied to conventional and alternative diesel blends (DOE, 2016). This credit is often instated retroactively, so the existence of the credit from year to year is the subject of considerable uncertainty. Blenders arrange sharing provisions with alternative fuel producers in order to compensate biofuel production (Irwin, 2015). Various sharing agreements between producers and blenders including $25 \%, 50 \%, 75 \%$, and $100 \%$ of the $\$ 1.00 /$ gallon $(\$ 0.26 /$ liter) given to producers were explored. Blenders and producers were assumed to share the additional revenue from these credits according to such sharing contracts. A "producer's credit," or a credit given directly to producers instead of blenders, is the subject of current legislation in the U.S. Senate (Swoboda, 2016). If passed, this new credit would be paid to producers but would also likely be shared via market mechanisms. Thus, the $\$ 1.00 /$ gallon $(\$ 0.26 /$ liter $)$ credit represents an optimistic, upper-limit value for a credit given to producers. Because the FT MSW feed composition contains unseparated biogenic and non-biogenic components, it was ineligible for the blender's or producer's credits.

Six different scenarios were examined in this study to reflect future legislative uncertainty: a "no policy" case in which the pathways were evaluated without the benefit of policy supports; a "pessimistic" case in which the blender's credit was not renewed at the 
conclusion of 2016 and the RVO falls to zero at the conclusion of 2022; and four different sharing arrangements with $25 \%, 50 \%, 75 \%$, and $100 \%$ of a $\$ 1.00 /$ gallon $(\$ 0.26 /$ liter $)$ excise tax credit given to producers along with a perpetual RIN market. Note that a zero RVO eliminates the demand for RINs, thereby removing the RIN revenue stream.

\section{Results and discussion}

\subsection{MSP and NPV}

The MSP and NPV were first calculated without the addition of policy supports or financial incentives. Box-and-whisker comparisons of each pathway's MSP and NPV results are shown in Figures 1 and 2, with the limits of each pathway result representing the middle $95 \%$ of values. The lowest mean MSP was that of HEFA yellow grease with a value of $\$ 0.91 /$ liter (95\% range of $\$ 0.66 /$ liter- $\$ 1.24 /$ liter), followed by HEFA tallow with a mean MSP value of $\$ 1.06 /$ liter $(\$ 0.79 /$ liter- $\$ 1.42 /$ liter), FT with $\$ 1.15 /$ liter $(\$ 0.95 /$ liter-

\$1.39/liter), HEFA soybean oil with \$1.19/liter (\$0.87/liter-\$1.60/liter), AF sugarcane at \$1.47/liter (\$1.10/liter-\$1.96/liter), FPH with \$1.52/liter (\$1.02/liter-\$2.10/liter), AF corn grain with $\$ 1.66 /$ liter $(\$ 1.30 /$ liter- $\$ 2.10 /$ liter), APP with $\$ 2.07 /$ liter $(\$ 1.73 /$ liter- $\$ 2.48 /$ liter), AF herbaceous biomass with $\$ 2.51 /$ liter $(\$ 2.16 /$ liter- $\$ 2.92 /$ liter), and HTL with $\$ 2.78 /$ liter (\$2.09/liter-\$3.58/liter). None of the MSP results approached the 5-year average conventional jet fuel price of $\$ 0.64 / \mathrm{L}$, even at the lower-bound values (EIA, 2016d). 


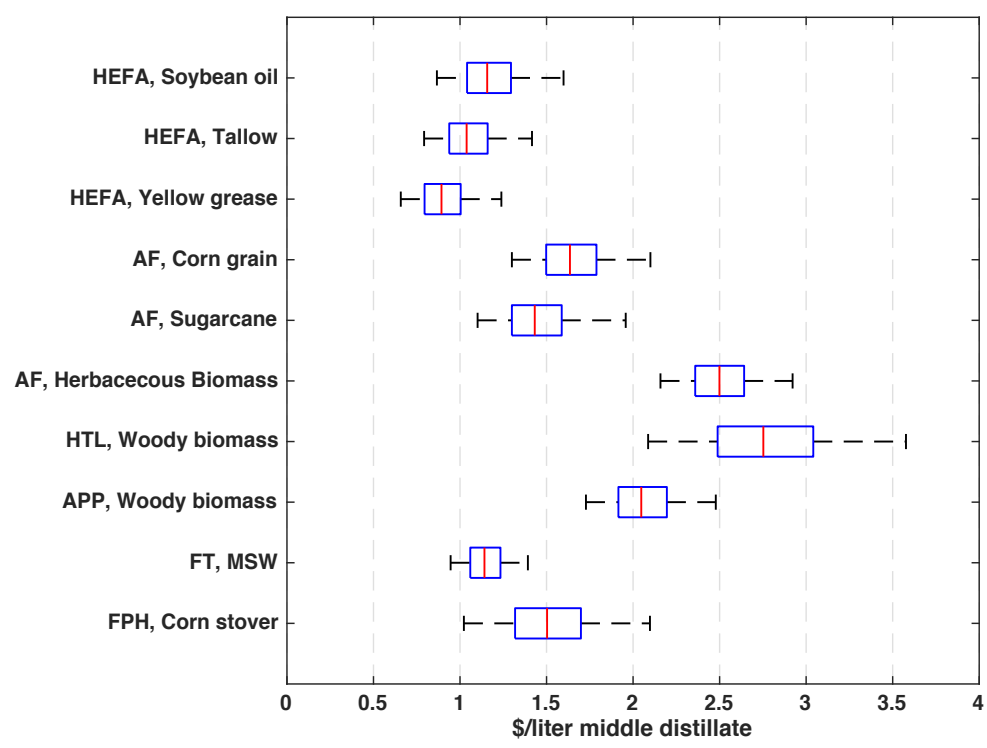

Figure 1. Box-and-whisker plot of the MSP results for each pathway evaluated in this study.

The mean future middle distillate prices were subject to considerable uncertainty over time, and the volatility of price behavior was accounted for with NPV calculations that incorporated projected prices of middle distillate fuels. None of the pathway simulations resulted in positive mean NPV values, although HEFA and FT exhibited positive NPV values at the upper bound of the results distribution. The highest mean NPV was that of HEFA yellow grease with a mean value (in \$B) of -0.112 (95\% range of $-0.412-0.179)$, followed by HEFA tallow with -0.202 (-0.517-0.100), FT with -0.210 (-0.424-0.033), HEFA soybean oil with $-0.281(-0.625-0.049)$, AF sugarcane with $-0.420(-0.775--0.099)$, AF corn grain with -0.552 (-0.905- -0.216), FPH with -0.344 (-0.583- -0.070), APP with $0.716(-1.005--0.408)$, HTL with $-0.854(-1.120--0.560)$, and AF herbaceous biomass with -1.036 (-1.336- -0.716). 


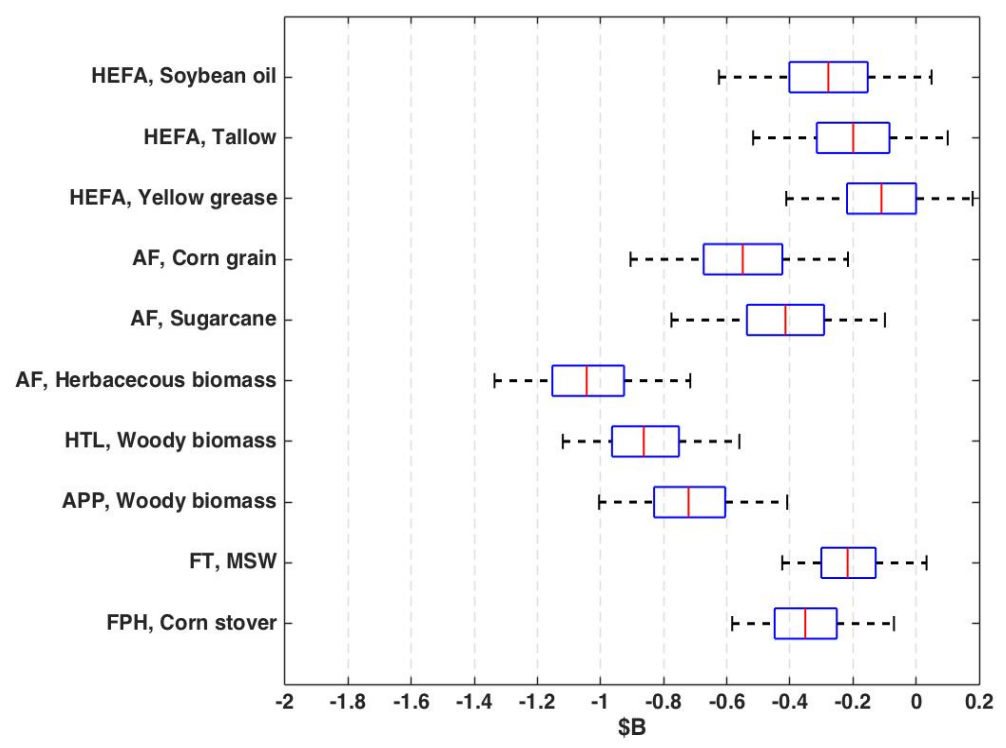

Figure 2. Box-and-whisker plot of the NPV over the 20-year lifetime for each pathway evaluated in this study.

The cumulative density functions of the NPV results are shown in Figure 3 and the baseline probabilities of positive NPV over each plant's lifetime are shown in Figure 5 (in the "No Policy" case). HEFA demonstrated the highest probability of positive NPV with a $27.7 \%, 14.8 \%$, and $8.6 \%$ chance of positive NPV for yellow grease, tallow, and soybean oil, respectively. HEFA and FT exhibited the lowest mean MSP and the least negative NPV due to a combination of factors: in the HEFA case, low capital investment requirements and high fuel yields outweighed relatively high feedstock costs. In the case of FT, these results stemmed from high fuel yields, no-cost feedstock, and comparatively low capital investment. 


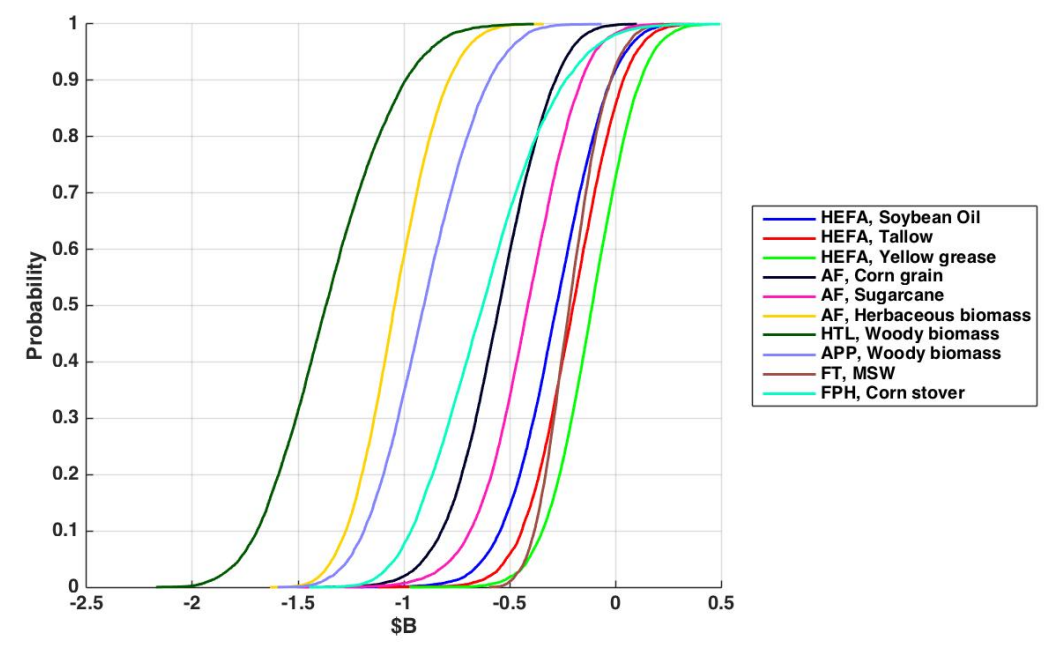

Figure 3. The cumulative density function (CDF) for the NPV results for each pathway.

An evaluation of the NPV contributors to variance revealed that yearly fuel price deviations primarily explained the variance in the NPV results for AF herbaceous biomass, APP, FT, HTL, and FPH, at 39\%, 48\%, 49\%, 64\%, and 56\%. The primary contributor for HEFA, AF corn grain, and AF sugarcane was feedstock cost. The feedstock cost distribution was negatively skewed which explains the negative skewness of the NPV distributions for these pathways. More information regarding the skewness and kurtosis of distributions fit to the Monte Carlo results can be found in SOM3, Table S7. Note that the variance for each pathway was influenced by the availability of data for the underlying distributions. In some cases, feedstock prices were based off of industry heuristics rather than historical price behavior. The price for herbaceous or woody biomass, for example, relied on low, mode, and high values from relevant literature sources surveying similar cellulosic biofuel refineries. The price for soybean oil and slaughtering byproducts, meanwhile, was described by a lognormal distribution derived from historical commodity prices. A survey of the contributors to variance for each pathway can be found in SOM 3. 
The MSP and NPV results for each pathway were separated into their constituent cost and revenue streams as shown in Tables 2 and 3. Only the mean values were reported in this table, and the median and standard deviations for each component can be found in SOM 3. For NPV, the revenue stream components were separated into gasoline/naphtha, middle distillate fuels, other co-products, and scrap materials. Due to the sorting requirement during the MSW pre-processing stage, only the FT pathway collected revenue from scrap materials. The cost stream components were separated into capital costs, fixed operating expenditures, non-feedstock variable operating expenditures, feedstock expenditures, and income tax.

\begin{tabular}{ccccccccccc}
\hline & $\begin{array}{c}\text { HEFA } \\
\text {-SO }\end{array}$ & $\begin{array}{c}\text { HEFA } \\
\text {-T }\end{array}$ & $\begin{array}{c}\text { HEFA } \\
\text {-YG }\end{array}$ & $\begin{array}{c}\text { AF }- \\
\text { CG }\end{array}$ & AF -S & $\begin{array}{c}\text { AF - } \\
\text { HB }\end{array}$ & HTL & APP & FT & FPH \\
\hline Capital costs & 0.20 & 0.20 & 0.20 & 0.56 & 0.64 & 1.26 & 2.41 & 1.38 & 0.93 & 1.21 \\
Fixed OPEX & 0.07 & 0.07 & 0.07 & 0.12 & 0.14 & 0.27 & 0.44 & 0.15 & 0.26 & 0.19 \\
Non-Feedstock & & & & & & & & & & \\
Variable OPEX & 0.12 & 0.12 & 0.12 & 0.14 & 0.03 & 0.44 & 0.62 & 0.63 & 0.08 & 0.76 \\
$\quad$ Feedstock & 0.85 & 0.73 & 0.58 & 1.02 & 0.69 & 0.46 & 0.70 & 0.38 & 0.00 & 0.15 \\
$\quad \begin{array}{c}\text { Income tax } \\
\text { Revenue from }\end{array}$ & 0.02 & 0.02 & 0.02 & 0.07 & 0.07 & 0.14 & 0.29 & 0.16 & 0.11 & 0.65 \\
$\quad \begin{array}{c}\text { gasoline } \\
\text { Revenue from other } \\
\text { co-products }\end{array}$ & -0.02 & -0.02 & -0.02 & -0.02 & -0.02 & -0.02 & -1.36 & -0.26 & -0.13 & -1.31 \\
Revenue from scrap & 0 & -0.04 & -0.04 & -0.30 & -0.13 & -0.04 & -0.41 & -0.40 & 0.00 & -0.19 \\
\hline
\end{tabular}

Table 2. Mean MSP (\$/liter) results breakdown by cost and revenue contributions. 


\begin{tabular}{ccccccccccc}
\hline & $\begin{array}{c}\text { HEFA } \\
\text {-SO }\end{array}$ & $\begin{array}{c}\text { HEFA } \\
- \text {-T }\end{array}$ & $\begin{array}{c}\text { HEFA } \\
\text {-YG }\end{array}$ & $\begin{array}{c}\text { AF - } \\
\text { CG }\end{array}$ & AF -S & $\begin{array}{c}\text { AF - } \\
\text { HB }\end{array}$ & HTL & APP & FT & FPH \\
\hline Capital costs & -129 & -129 & -129 & -369 & -421 & -803 & -682 & -798 & -533 & -410 \\
Fixed OPEX & -48 & -48 & -48 & -81 & -92 & -175 & -119 & -85 & -149 & -63 \\
$\begin{array}{c}\text { Non-Feedstock } \\
\text { Variable OPEX }\end{array}$ & -80 & -80 & -80 & -121 & -23 & -285 & -372 & -375 & -49 & -242 \\
$\quad$ Feedstock & -552 & -472 & -375 & -666 & -446 & -291 & -196 & -218 & -- & -218 \\
$\quad \begin{array}{c}\text { Income tax } \\
\text { Revenue from middle } \\
\text { distillate fuels }\end{array}$ & -5 & -7 & -13 & -2 & -7 & -- & -1 & -5 & -26 & -8 \\
$\begin{array}{c}\text { Revenue from } \\
\text { gasoline/naphtha }\end{array}$ & 12 & 12 & 12 & 12 & 12 & 12 & 237 & 100 & 55 & 280 \\
$\begin{array}{c}\text { Revenue from other } \\
\text { co-products }\end{array}$ & 21 & 21 & 21 & 191 & 75 & 23 & 70 & 239 & 2 & 64 \\
Revenue from scrap & -- & -- & -- & -- & -- & -- & -- & -- & 57 & -- \\
\hline
\end{tabular}

Table 3. Mean NPV (\$B) results breakdown by cost and revenue contributions.

Although plant capacities were harmonized, the product distribution varied based on the literature material balances, with HEFA, AF, APP, and FT pathways optimized for middle distillate production and HTL and FPH optimized for total fuel production. In the cases of HEFA, AF, APP, and FT, middle distillate fuels comprised the largest portion of the revenue stream. Because HTL and FPH produce more gasoline then middle distillates, the largest contributor to the revenue stream for those pathways was gasoline. The revenue contributions to NPV for each pathway were larger in cases where pathways produce additional non-liquid-fuel products. This was true for AF corn grain, a byproduct of which is distiller's dried grains with solubles (DDGS); AF sugarcane, a byproduct of which is sugarcane bagasse used to generate power; APP, a byproduct of which is hydroxymethylfurfural (HMF) and acetic acid; FT, a byproduct of which is scrap materials; and FPH, a byproduct of which is generated electricity from the heat of the pyrolysis reaction. The price of feedstock was the primary cost contributor to MSP and NPV for 
HEFA, AF corn grain, and AF sugarcane, and capital investment was the largest cost contributor to MSP and NPV for AF herbaceous biomass, HTL, APP, FT, and FPH. Fixed operating expenditures, which include maintenance, labor, and other yearly cost requirements, contributed an average of $9 \%$ and at most $20 \%$ to the cost stream for each pathway. Non-feedstock variable operating expenses, such as wastewater treatment, catalyst costs, and other utilities, comprised an average of $15 \%$ and at most $27 \%$ of the cost stream for each pathway.

The impact of different critical variables on MSP were examined with a sensitivity analysis for each pathway, quantifying the impact of adjustments to fixed operating costs, capital investment, fuel yield, income tax rate, feedstock costs, and the discount rate. The results are shown in Figure 4. The discount rate, which resulted from the rate of required return for equity and loan interest rate for debt, had the largest impact on MSP for every case except for the HEFA pathway, which required the lowest capital investment among all pathways and was therefore less sensitive to rate of return assumptions. The discount rate had a larger impact for pathways with a larger capital investment requirement because higher discount rates minimized the value of future cash flows, thus increasing the price of middle distillates required to set NPV equal to zero over the plant's 20 -year lifetime. The upper-bound discount rate test value of $22 \%$ was taken from Blazy et al., who suggested that the discount rate could be this high in order to offset the risks associated with investment in alternative fuel production technologies (Blazy et al., 2016). This can increase the MSP by up to $40 \%$. The lower-bound discount rate value of $3.2 \%$ came from the social opportunity cost of capital based on long-term treasury bond rates from the U.S. Office of Management and Budget (U.S. OMB, 2015). Use of this value can decrease MSP 
by up to $60 \%$. The pathways with the lowest mean MSP under the social opportunity cost of capital were FT and FPH with a mean MSP of $\$ 0.58 / \mathrm{L}$ and $\$ 0.61 / \mathrm{L}$, respectively. The fuel yield sensitivity analysis tested the outer bounds of the beta PERT distributions used for each pathway. Since the distributions were skewed negatively, the mode fuel yield value was close to the maximum so increases in fuel yield fail to lower mean MSP more than $20 \%$. Similarly, varying fixed operating costs to extreme values changed the mean MSP only up to $14 \%$. Although decreasing capital costs to $80 \%$ of the deterministic value improved mean MSP results, increasing those costs to $150 \%$ of the deterministic value increased mean MSP values by up to $50 \%$, indicating that cost overruns inhibited the economic viability of a given pathway. In order to explore the impact of feedstock cost on the FT pathway, which owed its probability of positive NPV and low mean MSP in part to a zero feedstock cost, the cost was varied by $\$ 55 / \mathrm{MT}$ both positively and negatively to reflect average landfill tipping fees. Although this could be a source of revenue in the short run, this tipping fee could become a cost if MSW is increasingly used as a feedstock for fuel production. Both cases adjusted the mean MSP by $15 \%$ positively or negatively. The income tax rate was varied between $0 \%$ and $39 \%$ with the upper bound chosen to reflect the 2015 U.S. combined corporate income tax rate (OECD, 2016). This value increased the mean MSP by up to $20 \%$. 

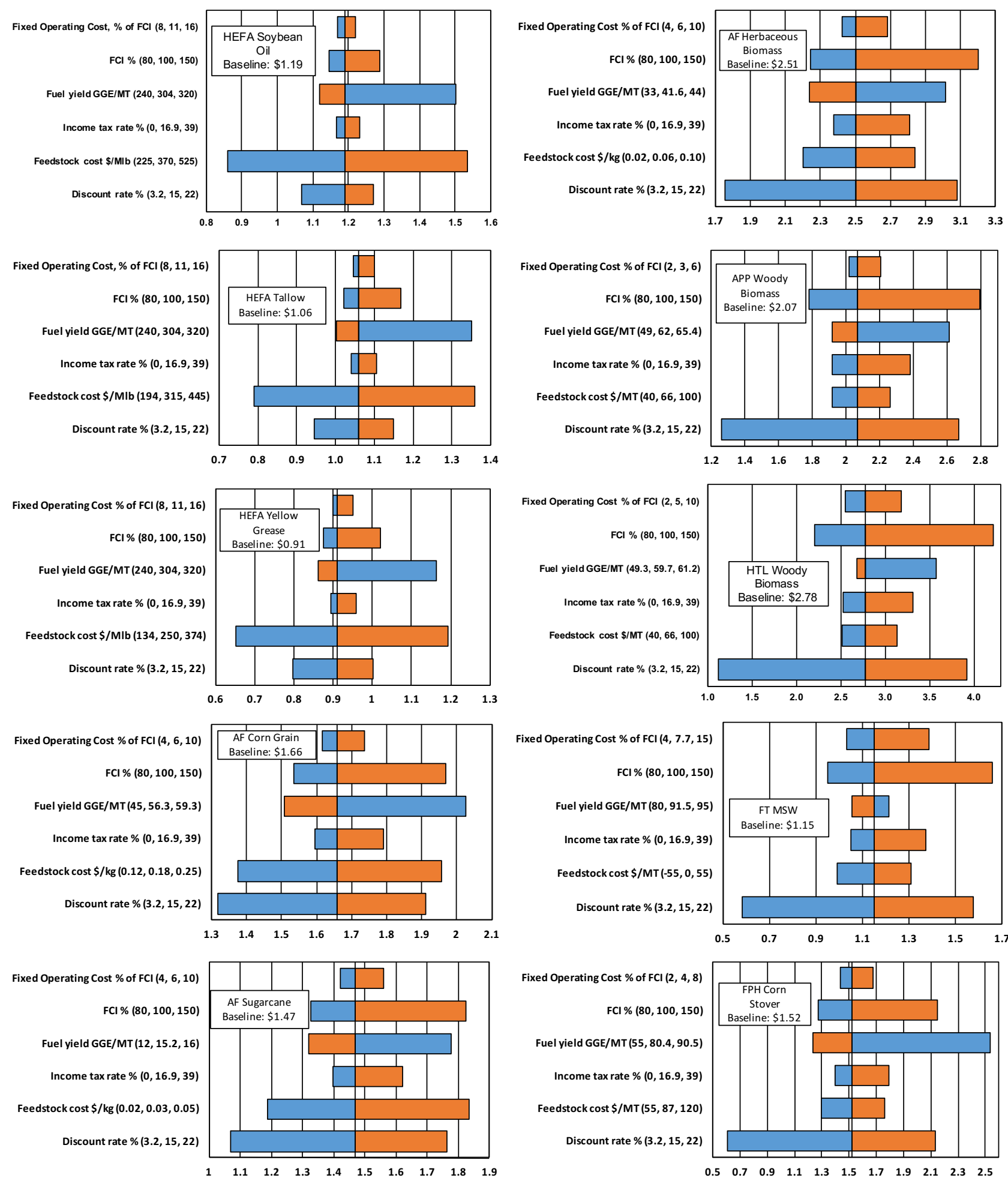

Figure 4. MSP sensitivity results for each pathway. All values expressed are mean values in units of \$/liter. The variables and associated test inputs are listed on the left axis (low, baseline, high). 


\subsection{Policy scenario analysis}

To quantify the impact of different policy environments on the economic viability of alternative fuel production techniques, the NPV for each pathway was calculated and the cumulative density distribution was used to find the probability of positive NPV. The results of this analysis are shown in Figure 5. The HEFA pathway showed the highest likelihood of positive NPV in a case with no policy supports for alternative fuels, with each of the three evaluated feedstocks outperforming the other pathways $(27.7 \%$ for HEFA yellow grease, $14.8 \%$ for HEFA tallow, and $8.56 \%$ for HEFA soybean oil). Under the "pessimistic" policy case with no blender's credit and a zero RVO, HEFA yellow grease, HEFA tallow, and FPH had the highest probability of positive NPV at 53.2\%, 34.9\%, and $23.5 \%$, respectively. FPH performed better under this scenario because the pathway used corn stover, a cellulosic feedstock, and therefore earned higher-value D3 and D7 RINs. HEFA, meanwhile, earned D4 and D5 RINs because it uses soybean oil and animal fats as feedstocks. Under the $50 \%$ credit-share and RIN market policy case, FPH, HEFA yellow grease, and HEFA tallow had the highest probability of positive NPV at $99.2 \%, 87.7 \%$, and 73.1\%. This was due to the higher value of D3 and D7 RINs relative to D4 and D5 RINs. Although FT had a 7.87\% probability of positive NPV under the "no policy" case, fuels produced from MSW only earned a D5 Advanced Biofuel RIN and were not subject to blender's credits, so the maximum probability of positive NPV for FT was only $37.8 \%$. Under the $100 \%$ credit-share case, five of the 10 feedstock-pathway combinations resulted in a $50 \%$ chance of positive NPV or higher: FPH, HEFA yellow grease, HEFA tallow, HEFA soybean oil, and APP have positive NPV probabilities of 99.7\%, 94.9\%, 86.6\%, $73.4 \%$, and $57.6 \%$, respectively. 


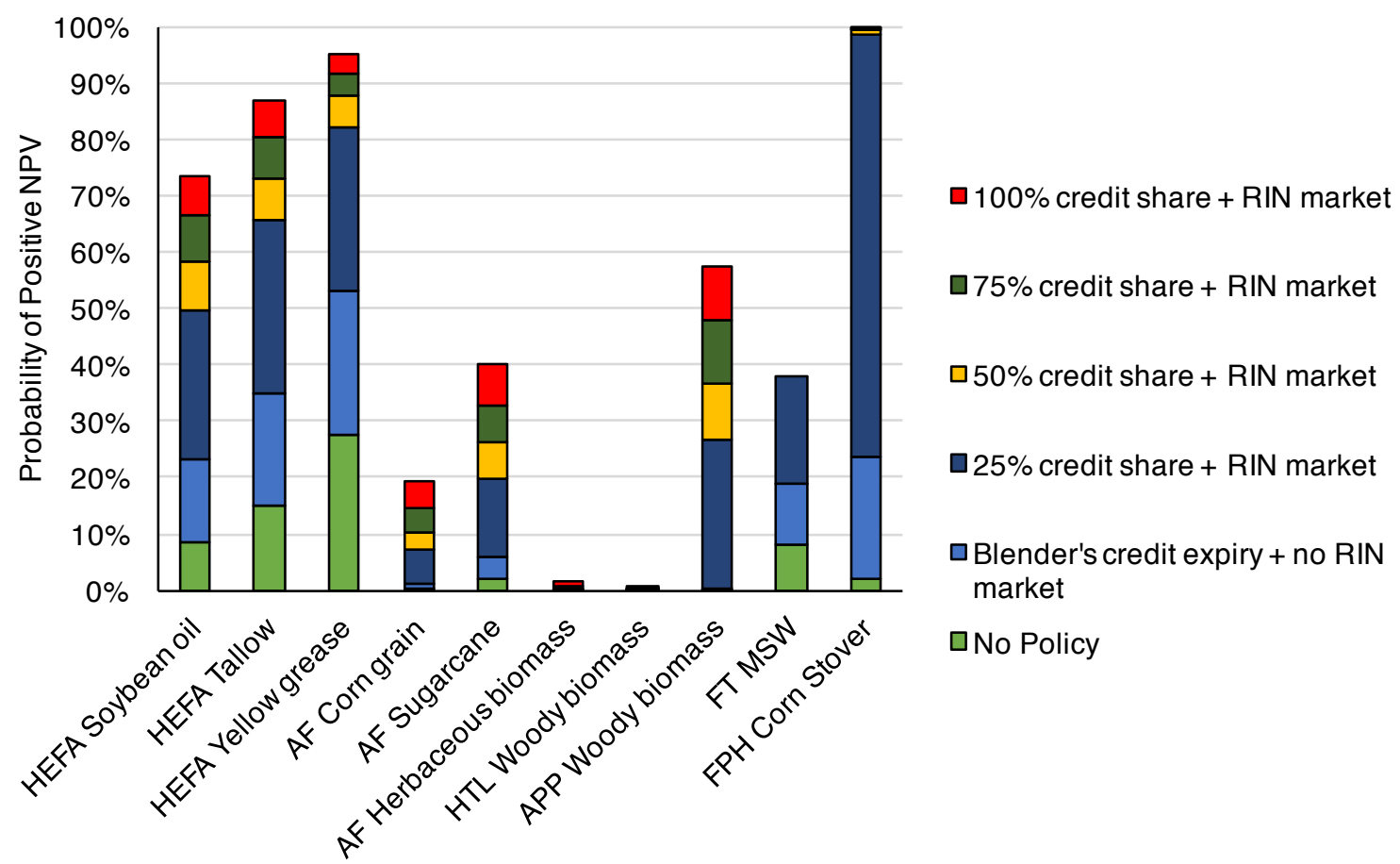

Figure 5. The probability of positive NPV over each pathway's 20-year plant lifetime under various policy scenarios. The "No Policy" case describes the results presented in section 3.1.

Other policy supports or corporate agreements, although not modeled in this study, could de-risk alternative jet fuel production investments and improve the economic viability of each pathway. The Department of Energy (DOE) loan guarantee program, for example, offers loans to biofuel ventures with no required payment in the event of bankruptcy (DOE, 2015). Offtake agreements, which can improve the borrowing terms associated with a project and further reduce costs, are contracts between fuel consumers and producers specifying the procurement of specified fuel volumes for a period of time, and have recently been agreed upon with several airlines (CAAFI, 2016). Similarily, longterm contracts for feedstock purchases could also reduce feedstock costs. Bittner et. al. models loan guarantees and offtake agreements as capital subsidies and reverse auctions: in each case, implementation of these scenarios decreases the risk of capital investment 
through decreased probabilities of loss and increased internal rates of return (Bittner et al., 2015). The impact of government policies and corporate agreements on the success of alternative jet fuel refineries could be evaluated further in the context of existing commercial ventures.

\section{Conclusions}

This study conducted a harmonized comparison of U.S. alternative jet fuel production that used stochasticity in key variables. The models also applied existing United States policy incentives to an evaluation of renewable jet fuels production pathways. The results suggest that no pathway is viable without policy supports, but regulations can improve the possibility of renewable diesel or jet fuel competition in the market. The MSP and NPV results for each pathway can be used by regulatory agencies to craft policies that favor alternative jet fuel production and can be leveraged by investors to target promising feedstock conversion technologies.

\section{Acknowledgements}

This work was supported by MIT Lincoln Laboratory [FA8721-05-C-0002]. The findings expressed in this article are those of the authors and do not reflect the official policy or position of the U.S. Department of the Army, the U.S. Department of Defense, or the U.S. Government. 


\section{References}

[1] Bittner, A., Tyner, W.E., Zhao, X., 2015. Field to flight: A techno-economic analysis of the corn stover to aviation biofuels supply chain. Biofuels, Bioproducts, \& Biorefining. 9, 201-210. doi: 10.1002/bbb.1536

[2] Blazy, D., Pearlson, M.N., 2016. A Monte Carlo-based Methodology for Valuing Refineries Producing Aviation Biofuel. doi:10.1039/9781782622444-00336

[3] Boeing, 2015. "Long Term Outlook," Current Market Outlook: 2015-2034, 7-9.

[4] Bond, J.Q., Upadhye, A. a., Olcay, H., Tompsett, G. a., Jae, J., Xing, R., Alonso, D.M., Wang, D., Zhang, T., Kumar, R., Foster, A., Sen, S.M., Maravelias, C.T., Malina, R., Barrett, S.R.H., Lobo, R., Wyman, C.E., Dumesic, J. a., Huber, G.W., 2014. Production of renewable jet fuel range alkanes and commodity chemicals from integrated catalytic processing of biomass. Energy Environ. Sci. 7, 1500-1523. doi:10.1039/C3EE43846E

[5] Brown, T.R., 2015. A critical analysis of thermochemical cellulosic biorefinery capital cost estimates. Biofuels, Bioproducts, \& Biorefining. 9, 412-421. doi: 10.1002/bbb. 1546

[6] Brown, T.R., Thilakaratne, R., Brown, R.C., Hu, G., 2013. Techno-economic analysis of biomass to transportation fuels and electricity via fast pyrolysis and hydroprocessing. Fuel 106, 463-469. doi:10.1016/j.fuel.2012.11.029

[7] CAAFI Commercial Aviation Alternative Fuels Initiative, 2016. Opening remarks by Steve Csonka, $5^{\text {th }}$ Biennial General Meeting, Oct 252016. http://caafi.org/information/pdf/Biennial Meeting Oct252016 Opening Remarks.pdf [accessed Dec 5 2016]

[8] de Jong, S., Hoefnagels, R., Faaij, A., Slade, R., Mawhood, R., Junginger, M., 2015. The feasibility of short-term production strategies for renewable jet fuels - a comprehensive techno-economic comparison. Biofuels, Bioprod. Biorefining 9, 778800. doi:10.1002/bbb.1613

[9] DOE, 2015. U.S. Department of Energy Loan Programs Office: Investing in American Energy.

[10] DOE, 2016. Alternative Fuels Data Center: Biodiesel Mixture Excise Tax Credit.

[11] Economic Indicators, 2016. Chemical Engineering. 123, 68.

[12] EIA, 2015. Annual Energy Outlook, vol. 2015.

[13] EIA, 2016a. Average Industrial Retail Price of Electricity, vol. 2016.

[14] EIA, 2016b. Cushing, OK WTI Spot Price FOB, vol. 2016.

[15] EIA, 2016c. Mont Belvieu, TX Propane Spot Price, vol. 2016.

[16] EIA, 2016d. U.S. Kerosene-Type Jet Fuel Wholesale/Resale Price by Refiners, vol. 2016.

[17] EIA, 2016e. U.S. Natural Gas Industrial Price, vol. 2016.

[18] EIA, 2016f. U.S. No. 2 Diesel Wholesale/Resale Price by Refiners, vol. 2016.

[19] EIA, 2016g. U.S. Total Gasoline Wholesale/Resale Price by Refiners, vol. 2016.

[20] Federal Aviation Administration, 2012. Aviation Greenhouse Gas Emissions Reduction Plan.

[21] Gary, J.H., Handwerk, G.E., Kaiser, M.J., 2007. Petroleum Refining: Technology and Economics. Taylor \& Francis: Basel, Switzerland. $5^{\text {th }}$ edn. 
[22] International Air Transportation Authority, 2009. Carbon Neutral Growth by 2020. Press Release no. 26.

[23] International Civil Aviation Organization, 2010. Aviation's Contribution to Climate Change. ICAO Environmental Report, 38-41.

[24] International Civil Aviation Organization, 2016. Chapter 4: Global Emissions: Sustainable Alternative Fuels. ICAO Environmental Report, 153-177.

[25] International Council on Clean Transportation, 2014. A conversational guide to Renewable Identification Numbers (RINs) in the U.S. Renewable Fuel Standard.

[26] Irwin, S., 2015. Why do blenders share retroactively reinstated tax credits with biofuel producers? Farmdoc Daily. University of Illinois at Urbana-Champaign Department of Agricultural and Consumer Economics.

[27] Niziolek, A.M., Onel, O., Hasan, M.M.F., Floudas, C.A., 2014. Municipal solid waste to liquid transportation fuels - Part II: Process synthesis and global optimization strategies. Comput. Chem. Eng. doi:10.1016/j.compchemeng.2014.10.007

[28] Organisation for Economic Co-operation and Development (OECD), 2016. Tax database, Table II.1: Corporate income tax rate.

[29] Pearlson, M., Wollersheim, C., Hileman, J., 2013. A techno-economic review of hydroprocessed renewable esters and fatty acids for jet fuel production. Biofuels, Bioproducts, \& Biorefining. 7, 89-96. doi: 10.1002/bbb.1378

[30] Peters, M.S., Timmerhaus, K.D., West, R.E., 2003. Plant design and economics for chemical engineers. McGraw-Hill Higher Education: New York, New York. $5^{\text {th }}$ edn.

[31] Petter, R. Tyner, W.E., 2014. Technoeconomic and policy analysis for corn stover biofuels. ISRN Economics. 2014, 1-13. doi: 10.1155/2014/515898

[32] Schäfer, A.W., Evans, A.D., Reynolds, T.G., Dray, L., 2015. Costs of mitigating CO2 emissions from passenger aircraft. Nat. Clim. Chang. 6, 2011-2014. doi:10.1038/nclimate2865

[33] Seber, G., Malina, R., Pearlson, M.N., Olcay, H., Hileman, J.I., Barrett, S.R.H., 2014. Environmental and economic assessment of producing hydroprocessed jet and diesel fuel from waste oils and tallow. Biomass and Bioenergy 67, 108-118. doi:10.1016/j.biombioe.2014.04.024

[34] Staples, M.D., Malina, R., Olcay, H., Pearlson, M.N., Hileman, J.I., Boies, A., Barrett, S.R.H., 2014. Lifecycle greenhouse gas footprint and minimum selling price of renewable diesel and jet fuel from fermentation and advanced fermentation production technologies. Energy Environ. Sci. 7, 1545. doi:10.1039/c3ee43655a

[35] Stephens, M. A., 1974. EDF Statistics for goodness of fit and some comparisons. Journal of the American Statistical Association. 347, 730-737. doi: 10.1080/01621459.1974.10480196

[36] Suresh, P., 2016. Environmental and economic assessment of transportation fuels from municipal solid waste. Thesis for Master of Science in Aeronautics and Astronautics at the Massachusetts Institute of Technology.

[37] Swoboda, R., 2016. Iowa Senators support biodiesel tax credit extension. American Agriculturist.

[38] United States Government Accountability Office, 2013. Corporate Income Tax: Effective Tax Rates Can Differ Significantly from the Statutory Rate, Report GAO-13520. 
[39] U.S. OMB, 2015. Discount rates for cost-effectiveness, lease purchase, and related analyses. Circular A-94 Appendix C.

[40] Winchester, N., McConnachie, D., Wollersheim, C., Waitz, I.A., 2013. Economic and emissions impacts of renewable fuel goals for aviation in the US. Transp. Res. Part A Policy Pract. 58, 116-128. doi:10.1016/j.tra.2013.10.001

[41] Zhao, X., Brown, T.R., Tyner, W.E., 2015. Stochastic techno-economic evaluation of cellulosic biofuel pathways. Bioresour. Technol. 198, 755-763. doi:10.1016/j.biortech.2015.09.056

[42] Zhu, Y., Biddy, M.J., Jones, S.B., Elliott, D.C., Schmidt, A.J., 2014. Techno-economic analysis of liquid fuel production from woody biomass via hydrothermal liquefaction (HTL) and upgrading. Appl. Energy 129, 384-394.

doi:10.1016/j.apenergy.2014.03.053 